Original Article

\title{
RELEVANCE OF MEASUREMENT OF HEM ATOLOGICAL PARAMETERS IN SUBJECTS WITH PREGNANCY INDUCED HYPERTENSION
}

\author{
Gearaldine Monteiro ${ }^{1}$, Subbalakshmi N.K. ${ }^{2} \&$ Sheila R. Pai ${ }^{3}$ \\ ${ }^{1}$ Tutor, ${ }^{2}$ Associate Professor, ${ }^{3}$ Professor, Department of Physiology, Kasturba M edical College, M anipal University, \\ Light House Hill Road, Mangalore, Karnataka, INDIA \\ Correspondence: \\ Subbalakshmi N.K. \\ Associate Professor, Kasturba M edical College, Manipal University, Light House Hill Road, \\ Mangalore-575001, Karnataka, India \\ Mobile : +91 94839 10879, Fax : +91 8242428183 E-mail : rao.subbalakshmink@rediffmail.com
}

\begin{abstract}
:
Background: The pregnancy induced hypertensive (PIH) mothers are at greater risk for intrauterine growth restriction (IUGR) and intrauterine death of foetus (IUD). But currently there are no suitable early indicators of PIH mothers at risk of IUGR and IUD.

Aims/ objectives: To assess the various routinely measured hematological parameters in assessment of PIH mothers at risk of IUGR and IUD.

Methods: This was a retrospective study done in singleton mothers. Study Group: 75 subjects with PIH. They were divided in to: Group A ( $n=35)$ : PIH subjects with IUGR and IUD. Group B ( $n=40)$ : PIH subjects without IUGR and IUD. Controls: 62 normotensives. Blood parameters measured were: platelets, packed cell volume (PCV), hemoglobin, erythrocyte sedimentation rate (ESR), differential leucocyte count. Statistical analysis was done by ANOVA and Bonferroni test. $P \varangle 0.05$ wastaken as significant.
\end{abstract}

Results: Among the measured blood parameters, platelet count was lower in group $A$ and group $B$ compared to control $(p<0.0001)$. Platelets were also lower in group $A$ compared to group $B(p \varangle 0.0001)$. Hemoglobin and PCV were lower in group A compared to controls and group $B(p \varangle 0.001)$. M onocytes and ESR were lower in group $A$ and group $B$ compared to controls $(p \varangle 0.05, p \varangle 0.001$ respectively). Neutrophils were lower in group A compared to control $(p \varangle 0.05)$. Other pairwise comparisons did not differ significantly.

Conclusions: Platelet count may be a suitable marker in monitoring subjects with PIH at risk of IUGR and IUD. Anemia may be associated with IUD and IUGR in PIH patients.

Keywords: Pregnancy induced hypertension, platelet count, hemoglobin, packed cell volume

\section{Introduction:}

The hypertensive disorders during pregnancy affect up to $8.0 \%$ of all pregnancies ${ }^{(1)}$ and remain a major cause of maternal and neonatal mortality and morbidity worldwide. ${ }^{(2 \text { and } 3)}$ In women with pre-eclampsia, a history of symptoms is obtained antenatally, with the key alarming clinical symptoms being Access this article online Quick Response Code

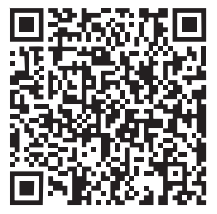
headache, vomiting, visual disturbances and epigastric pain. However the unpredictable onset and progression of these symptoms warrants the need for an early and appropriate detection. ${ }^{(4)}$

The association between proteinuria and pre-eclampsia has long been established and its presence is diagnostic of the disease and is indicative of its multisystem nature leading to maternal and foetal morbidity and mortality. ${ }^{(5, \text { and }}$ 6) However, recent studies on pre-eclampsia with varying levels of proteinuria have pointed out that estimation of levels of proteinuria in women with pre-eclampsia do not correlate with maternal and foetal outcomes. ${ }^{(7 \text { and } 8)}$ Thus urinary protein estimation may not be a clinically useful predictive test, disputing the practice of deciding on delivery based on the severity of proteinuria.

Over the years, a lot of interest has been directed at studies 
on the role of serum uric acid, urea and creatinine in the pathogenesis of pregnancy induced hypertension. ${ }^{(9 \text { and10) }}$ At the same time hypertensive disorders account for $21 \%$ of cases of thrombocytopenia in pregnancy ${ }^{(11)}$ and the risk of anemia may also increase with the severity of hypertensive disorders. ${ }^{(12)}$ Thus, though the roles of serum urea, uric acid and creatinine have been studied by many researchers, ${ }^{13)}$ there is a constant ongoing search for better predictors and prognostic factors to assess the progress and severity of the disease, hematological parameters being one among them. ${ }^{(14)}$ Currently there are no individual screening tests that are reliable, valid, and economical. ${ }^{(15)}$ With this background of knowledge, the present study was undertaken to evaluate the relevance of routinely done renal functions and hematological parameters in assessment of pregnancy induced hypertension.

\section{Materials And Methods:}

The present study was a retrospective, descriptive type. It was carried out at the Lady Goschen Hospital, M angalore. Study was done in eligible pregnancy induced hypertensive singleton mothers of whom relevant medical reports were available until they were discharged from the hospital after delivery.

Study subjects : 140 consecutive eligible cases were enrolled into the study. They were divided into two groups: 1. study group: Comprised of 75 subjects with pregnancy induced hypertension (PIH) and 2. Control group: Comprised of 65 normotensive mothers. The study group wasfurther subdivided into:

Group A ( $n=35)$ : PIH subjects with intrauterine growth retardation (IUGR) and intra uterine death of the foetus (IUD).

Group B $(n=40)$ : PIH subjects without IUGR and IUD of foetus.

Inclusion criteria: 1) Booked cases; 2) 25-35 years; 3) No history of hypertension in the past

4) Diagnosed to have pregnancy induced hypertension from twentieth week.

Exclusion criteria: 1) Subjects suffering from hemorrhagic diseases; 2) Thromboembolic episodes; 3) Epileptics; 4) on long term treatment with steroids, anticoagulants.

The following parameters were assessed: Hematological parameters: platelets, packed cell volume (PCV), hemoglobin, Erythrocyte Sedimentation Rate (ESR), total leucocyte count (TLC) and differential leucocyte count (DLC). Renal function parameters: serum urea, serum uric acid, serum creatinine, and urine protein. Apart from measurement of these parameters, random blood sugar, body mass indexes (BMI), systolic and diastolic blood pressure were noted.

Data analysis: Analysis of one way analysis followed by multiple comparisons (Bonferroni test) was applied. P value less than 0.05 was considered statistically significant.

\section{Results:}

Data is presented as mean \pm Standard deviation (SD). Comparison of baseline characteristics of control group (n =62) and subgroups of study subjects (Group A: PIH mothers with IUGR and IUD of foetus $(n=40)$; Group B: PIH mothers without IUGR and IUD of foetus ( $n=35$ ) is presented in table 1 . The control group, group $A$ and group $B$ was comparable with regard to age, body mass index and random blood sugar. Blood pressure and urine protein was significantly higher in group $A$ and group $B$ compared to control $(p<0.001$, table1).

Among the renal function parameters measured, serum creatinine did not differ significantly among the subjects of group A, group B and control (table 2). Serum urea was significantly higher in group $B$ compared to control $(p<$ $0.0001)$ and group $A(p<0.05)$. There was no significant difference in serum urea between group $A$ and control (table 2). Serum Uric acid was significantly higher in group $A$ and group $B$ compared to control ( $p \varangle .0001$ ). Serum urea of group A and group B did not differ significantly (table 2).

Total leucocyte count was significantly higher in group A and group $B$ compared to control $(p<0.001$ and $p<0.05$ 
Table 1 Data on baseline characteristics of pregnancy induced hypertensive and control subjects (Values are: M ean \pm SD)

NS =Non-significant compared to control; Non -significant group A compared to group

\begin{tabular}{|l|l|l|l|}
\hline Parameters & Control $\mathbf{( n = 6 5 )}$ & $\begin{array}{l}\text { PIH with normal foetus } \\
\text { Group B }(\mathbf{n}=\mathbf{4 0})\end{array}$ & $\begin{array}{l}\text { PIH with IUGR and } \\
\text { IUD of foetus }\end{array}$ \\
\hline Group A $(\mathbf{n = 3 5 )}$ & & & \\
\hline AGE (years) & $28.01 \pm 4.48$ & $29.9 \pm 3.50^{\mathrm{NS}}$ & $29.91 \pm 4.18^{\mathrm{NS}}$ \\
\hline $\mathrm{BMI}(\mathrm{kg} / \mathrm{m} 2)$ & $25.09 \pm 2.50$ & $26.63 \pm 2.64^{\mathrm{NS}}$ & $25.65 \pm 2.95^{\mathrm{NS}}$ \\
\hline $\mathrm{SBP}(\mathrm{mmHg})$ & $117.58 \pm 6.93$ & $158 \pm 7.90^{* * *}$ & $159.71 \pm 8.57^{* * *}$ \\
\hline $\mathrm{DBP}(\mathrm{mmHg})$ & $72.74 \pm 4.84$ & $98 \pm 5.16^{* * *}$ & $100.28 \pm 8.21^{* * *}$ \\
\hline Urine Protein & $5.5 \pm 1.04$ & $7.08 \pm 1.56^{* * *}$ & $6.76 \pm 1.51^{* * *}$ \\
\hline Random blood sugar $(\mathrm{mg} \%)$ & $102.61 \pm 21.43$ & $113.9 \pm 30.37^{\mathrm{NS}}$ & $115.31 \pm 27.725^{\mathrm{NS}}$ \\
\hline
\end{tabular}

B

$* * * p<0.0001$ compared to control

$\mathrm{PIH}=$ Pregnancy induced hypertension; IUGR = intrauterine growth restriction;

IUD = Intrauterine death; SBP = systolic blood pressure; $\mathrm{DBP}=$ diastolic blood pressure;

$\mathrm{BM} \mathrm{I}=$ Body Mass Index

Table 2 Renal parameters - serum levels in control and study subjects (Values are M ean \pm SD)

***P $<0.0001$ compared to control; $* p<0.05$ compared to group $\mathrm{B}$

\begin{tabular}{|l|l|l|l|}
\hline Parameters & Control $(\mathbf{n}=\mathbf{6 5})$ & PIH With normal foetus & PIH With IUGR AND IUD \\
\hline & & Group B ( $\mathbf{n}=\mathbf{4 0})$ & Group $\mathbf{A}(\mathbf{n}=\mathbf{3 5})$ \\
\hline Creatinine $(\mathrm{mg} \%)$ & $0.61 \pm 0.15$ & $0.67 \pm 0.18^{\text {NS }}$ & $0.64 \pm 0.19^{\text {NS }}$ \\
\hline Urea $(\mathrm{mg} \%)$ & $16.75 \pm 11.56$ & $27.5 \pm 16.26^{* * *}$ & $19.17 \pm 12.98^{* \text { NS }}$ \\
\hline Uric acid & $4.34 \pm 1.61$ & $5.83 \pm 1.61 \neq \neq \ddagger$ & $6.46 \pm 1.76 \neq \neq \ddagger$ \\
\hline
\end{tabular}

$\ddagger \ddagger \ddagger p \triangleleft 0.0001$ compared to control. NS=non-significant compared to control.

IUGR = intrauterine growth retardation; IUD = intrauterine death.

Table 3 Hematological parameters in control and study subjects (values are mean \pm SD)

\begin{tabular}{|l|l|l|l|}
\hline Parameters & Control $(n=65)$ & $\begin{array}{l}\text { PIH With normal foetus } \\
\text { Group } B(n=40)\end{array}$ & $\begin{array}{l}\text { PIH With IUGR and IUD } \\
\text { of foetus Group } A(n=35)\end{array}$ \\
\hline PCV & $31.49 \pm 4.08$ & $31.42 \pm 2.72^{\text {NS }}$ & $28.01 \pm 3.79 * *$ \\
\hline Hemoglobin & $10.8 \pm 2.72$ & $11.39 \pm 1.54^{\text {NS }}$ & $8.54 \pm 3.06^{* *}$ \\
\hline ESR & $38.04 \pm 21.93$ & $57.87 \pm 23.35 \dagger$ & $51.02 \pm 25.84 \dagger \dagger$ \\
\hline Platelets & $204161.29 \pm 71998.45$ & $121625 \pm 90055.44 \dagger \dagger$ & $106971.4286 \pm 89998.52 * *$ \\
\hline TLC & $10429.83 \pm 2828.37$ & $12679 \pm 3825.07 \ddagger$ & $13248.85 \pm 5528.81 \neq \ddagger$ \\
\hline Neutrophils & $74.69 \pm 7.41$ & $77.87 \pm 9.51^{\text {NS }}$ & $79 \pm 7.63^{*}$ \\
\hline Lymphocytes & $19.12 \pm 7.57$ & $17.82 \pm 7.87^{\text {NS }}$ & $21.37 \pm 7.66^{\text {NS }}$ \\
\hline Monocytes & $0.45 \pm 0.50$ & $0.82 \pm 0.84^{*}$ & $0.91 \pm 0.81^{*}$ \\
\hline Eosinophils & $0.93 \pm 0.97$ & $0.75 \pm 0.89^{\text {NS }}$ & $0.94 \pm 0.68^{\text {NS }}$ \\
\hline Basophils & $0.419 \pm 0.5$ & $0.675 \pm 0.61^{*}$ & $0.6 \pm 0.55^{\text {NS }}$ \\
\hline
\end{tabular}

PCV $=$ Packed Cell Volume

ESR $=$ Erythrocytes Sedimentation Rate

$\mathrm{TLC}=$ Total Leucocyte Count

$* * p<0.001$ compared to control and PIH with normal foetus (group B)

† $p<0.05$ compared to control; $* p<0.05$ compared to control

$\dagger \dagger p<0.01$ compared to control

$\ddagger p<0.05$ compared to control

$\neq \ddagger p<0.01$ Compared to control; NS =Compared to control 
respectively, table 3). Total leucocyte count did not differ significantly between group A and group B (table 3). Neutrophil count was significantly lower in group A compared to control $(p \varangle 0.05)$. Neutrophil count did not differ between control and group B. Neutrophil count was comparable between group $A$ and group $B$. Monocyte count was significantly lower in group $A$ and group $B$ compared to control $(p<0.05)$. Monocyte count did not differ significantly between group $A$ and group $B$. Eosinophil count did not differ significantly between control and study subjects (table 3). Basophil count was higher in group B compared to control. Basophil count of group A did not vary compared to control and group B (table 3).

PCV and hemoglobin concentration was significantly lower in group A compared to group B and control $(p<0.001)$. PCV and hemoglobin concentration did not differ significantly between control and group B (table 3).

Erythrocyte sedimentation rate (ESR) was significantly higher in group A and group B compared to control $(p<$ 0.001 and $p<0.05$ respectively, table 3 ). ESR did not differ significantly between group A and group B (table 3 ).

Platelet count was significantly lower in group $A$ and group B compared to control ( $p \varangle 0.001, p \varangle 0.01$ respectively, table 3). Platelet count was significantly lower in group $A$ compared to group $B(p<0.001$, table 3$)$.

\section{Discussion :}

Pregnancy induced hypertension is asso ciated with greater risk of IUGR and IUD of foetus. But currently there are no suitable indicators in monitoring the progression of $\mathrm{PIH}$ leading to IUGR and IUD of foetus. We evaluated the relevance of measurement of renal function and hematological parameters in PIH mothers.

In the present study, systolic and diastolic blood pressure was significantly higher in study subjects compared to control (table 1). But blood pressure of study subjects with normal foetus did not vary compared to PIH mothers with IUGR and IUD of foetus. Our finding is in agreement with the findings of Cnossen et al. who also have observed that systolic and diastolic blood pressures are poor predictors of pre-eclampsia. ${ }^{(16)}$ However in their study pre-eclampsia was considered unlike PIH mothers with IUGR and IUD of foetusin our study.

In the present study, urine protein was significantly higher in study subjects compared to control (table 1). But study subjects with and without IUGR and IUD of foetus were comparable with regard to urine protein. This finding suggests that although raised protein is a characteristic feature of PIH, this parameter may not be involved in the progression of pathogenesis of PIH leading to IUGR and IUD of foetus. Lao $T$ et al and Newman M G et al too did not find correlation between estimation of levels of proteinuria with maternal and foetal outcome in women with preeclampsia. ${ }^{(6 \text { and } 7)}$ Our finding is in agreement with the findings of Lao TT et al and New man M G et al.

In the present study, serum uric acid was significantly higher in study subjects compared to control (table 2). However, serum uric acid level was comparable between PIH subjects with and without IUGR and IUD of foetus (table 2). Findings of previous research work on association between uricemia and PIH is conflicting. Wake VC et al have observed that in subjects with pre-eclampsia plasma uric acid level will help to predict those that will develop eclampsia. ${ }^{(17)}$ Hawkins $A$ et al have reported that hyperuricemia in hypertensive pregnancy remains an important finding because it identifies women at increased risk of adverse foetal outcome even women with gestational hypertension without any other features of pre-eclampsia. ${ }^{(18)}$ In the study of Mustaphi R et al, high positive correlation was observed between levels of serum uric acid and severity of PIH in relation to hypertension and proteinuria. ${ }^{(19)}$ However, Hickman PE et al have noted serum uric acid as an unreliable indicator of developing hypertension in the individual women. ${ }^{(20)}$ Salako ABL et al have reported that single estimation of serum uric acid level early in pregnancy are of little value in the prediction of pre-eclampsia. ${ }^{(21)}$ However, our study finding suggests that with PIH, uric acid metabolism may get impaired but it may not be linked with pathogenesis of the disorder 
leading to IUGR and IUD of foetus.

In the present study total leucocyte count was higher in PIH mothers with or without IUGR and IUD of foetus compared to normotensive mothers (table 3). Monocyte count was significantly higher in PIH mothers irrespective of having IUGR and IUD of foetus compared to control (table 3). Neutrophil count was higher in PIH mothers with IUGR and IUD of foetus compared to control (table 3). Canzoneri BJ et al too have observed increase in total leucocyte count in PIH mothers. But in their study monocyte count did not vary between mothers with and without PIH. ${ }^{(22)}$ Pregnancy induced hypertension is a multisystem disorder and may involve inflammatory response. ${ }^{(23)}$ Thus variation in leucocyte count especially of neutrophils and monocytes observed in our study could be one of the clinical manifestations of underlying $\mathrm{PIH}$ pathogenesis. However, Sivakumar $\mathrm{S}$ et al have not observed any difference in total leucocyte count and differential neutrophil count in PIH mothers compared to normotensive mothers. ${ }^{(14)}$ In the present study, total leucocyte count and differential leucocyte count did not differ between PIH mothers with and without IUGR and IUD of foetus (table 3). Therefore it could be said that total and differential leucocyte count may not be a reliable marker in monitoring PIH subjects at greater risk for adverse foetal outcome.

In the present study, hemoglobin concentration and PCV did not differ significantly between normotensive mothers and PIH mothers with normal foetus. But PIH mothers with IUGR and IUD of foetus had significantly lower hemoglobin concentration and PCV compared to control and PIH mothers with normal foetus (table 3 ). This finding suggests that anemia is an associated risk factor for IUGR and IUD of foetus in PIH mothers. Maternal anemia is a common pregnancy complication in developing countries. Zhang et al have reported that the risk of anemia increases with the severity of hypertensive disorders. ${ }^{(24)}$ Therefore monitoring PCV and hemoglobin concentration may aid in better management of PIH mothers at risk of IUGR and IUD of foetus.
In the present study, platelet count was within normal range in normotensive mothers. But platelet count was lower in PIH mothers with or without IUGR and IUD of foetus compared to normotensive mothers. Further, platelet count was much lower in PIH mothers with IUGR and IUD of foetus compared to PIH mothers with normal foetus (table 3). Thus a decline in platelet count was associated with severity of PIH progressing to IUGR and IUD of foetus. Hypertensive disorders accounts for $21 \%$ of cases of thrombocytopenia in pregnancy ${ }^{(11)} \mathrm{Nazli}$ R et al too have reported high frequency of thrombocytopenia in $\mathrm{PIH}$ mothers. ${ }^{(25)}$ In their study the severity of thrombocytopenia was proportional to the severity of pregnancy related hypertensive disorders. ${ }^{(25)}$ In the study of Rahim et al $74.28 \%$ of low birth weight babies were observed in PIH mothers with thrombocytopenia. ${ }^{(26)}$ In the study by Hossain et al thrombocytopenia was associated with a higher prevalence of preterm delivery and intrauterine growth retardation; and was also found to be an independent and important risk factor in the occurrence of maternal and perinatal complications in pregnancy related hypertensive disorders. ${ }^{(27)}$ Our findings along with the observations of previous workers support the relevance of monitoring platelet count in PIH mothers especially at greater risk of adverse foetal outcome.

Thus based on our study findings, it could be concluded that among the hematological parameters measured, platelet count may be a suitable marker in monitoring subjects with PIH at risk of IUGR and IUD of foetus. Reduced hemoglobin and packed cell volume may be associated with IUGR and IUD of foetus in PIH mothers. Proteinuria, uricemia, higher ESR, higher total leucocyte count, higher neutrophil, monocyte and basophil counts are associated with PIH but does not reflect on PIH mothers at risk of IUGR and IUD of foetus.

DECLARATION OF INTEREST: No conflict of interest 


\section{References:}

1. Sullivan CA, Martin JN. Management of the obstetric patient with thrombocytopenia. Clin Obstet Gynecol 1995; 38: 521-34.

2. Cunningham FG, Kerneth JLleveno, Steven L. Bloom et al: Hypertensive Disorders in Pregnancy. In Williams Obstetrics.linternational edn, New york: M cgraw hill; 2001; chp-34, p. 567- 618.

3. Ferrazzani S, Luciano R, Garofalo S, D'Andrea V, De Carolis S, De Carolis MP, Paolucci V, Romagnoli C, Caruso A. Neonatal outcome in hypertensive disorders of pregnancy. Early Hum Dev. 2011; 87(6): 445 49.

4. Michelle Hladunewich, S Ananth Karumanchi, Richard Lafayette. Pathophysiology of the Clinical Manifestations of Preeclampsia. Clin J Am Soc Nephrol 2007; 2: 543-49.

5. Pollak VE, NettlesJB. The kidney in toxemia of pregnancy: a clinical and pathologic study based on renal biopsies. M edicine (Baltimore) 1960; 39: 469-52.

6. Lao TT, Chin RK, Lam YM. The significance of proteinuria in preeclampsia; proteinuria associated with low birth weight only in preeclampsia. EurJ Obstet Gynecol Reprod Biol 1988;29 (2):121-27.

7. Newman MG, Robichaux AG, Stedman CM, Jaekle RK, Fontenot MT, Dotson T, Lewis DF. Perinatal outcomes in preeclampsia that is complicated by massive proteinuria. Am. J. Obstet. Gynecol 2003; 188(1), $264-68$

8. Thangaratinam S, Coomarasamy A, O'Mahony F, Steve Sharp S, Zamora J, Khalid SKhan KS, Ismail KM K. Estimation of proteinuria as a predictor of complications of pre-eclampsia: a systematic review. BM C Medicine 2009; 7:10.

9. Egwuatu VE. Plasma concentration of urate, urea and creatinine in Nigerian primigravidae with pre-eclampsia. Trop Geogr Med 1986; 38:11-15.

10. Mustaphi R, Gopalan S, Dhaliwal L, Sarkar AK. Hyperuricemia and pregnancy induced hypertension-reappraisal. Indian J Med Sci 1996, 50: 68- 71 .

11. Shehata N, Burrows R, Kelton JG. Gestational thrombocytopenia. Clin Obstet Gynecol 1999; 42: 327-34.

12. Zhang Q, Li Z, Ananth CV. Prevalence and risk factors for anaemia in pregnant women: a population-based prospective cohort study in China. Paediatr Perinat Epidemiol. 2009; 23(4):282-91.

13. M anjareeka $M$, Nanda S. Elevated levels of serum uric acid, creatinine or urea in pre-eclamptic women. Int J M ed Sci Public Health 2013; 2(1): 43-47.
14. Sivakumar S, Bhat BV, Badhe BA. Effect of pregnancy induced hypertension on mothers and their babies. Indian J Pediatr 2007;74(7):623-25

15. Levine RJ, Lindheimer MD: First-trimester prediction of early preeclampsia: a possibility at last! Hypertension 2009; 53(5): 747-48.

16. Cnossen JS, Vollebregt KC, Vrieze ND, Riet GT, Ben W J M ol , Franx A. Accuracy of mean arterial pressure and blood pressure measurements in predicting pre-eclampsia: systematic review and meta-analysis. BMJ 2008; 336: 1117

17. Wakwe VC, Abudu 00. Estimation of plasma uric acid in pregnancy induced hypertension (PIH). Is the test still relevant? Afr J Med Med Sci 1999; $28(3-4): 155-58$.

18. Hawkins TL, Roberts JM , M angos GJ, Davis GK, Roberts LM , Brown M A. Plasma uric acid remains a marker of poor outcome in hypertensive pregnancy: a retrospective cohort study. BJOG 2012; 119(4):484-92.

19. Mustaphi R, Gopalan S, Dhaliwal L, Sarkar AK. Hyperuricemia and pregnancy induced hypertension-reappraisal .Indian J M ed Sci 1996; 50 (3):68-71.

20. Hickman PE, Michael CA, Potter JM. Serum uric acid as a marker of pregnancy-induced hypertension. Aust N ZJ Obstet Gynaecol. 1982; $22(4): 198-202$

21. Salako BL, Odukogbe AT, Olayemi O, Adedapo KS, Aimakhu CO, Alu FE, Ola B. Serum albumin, creatinine, uric acid and hypertensive disorders of pregnancy. East Afr M ed J 2003; 80(8):424-28.

22. Canzoneri BJ, Lewis DF, Groome L, Wang Y. Increased neutrophil numbers account for leukocytosis in women with preeclampsia. Am Perinatol 2009; 26 (10):729-32.

23. Schiessl B. Inflammatory response in preeclampsia. Mol Aspects M ed 2007; $28(2): 210-19$.

24. Zhang Q, Li Z, Ananth CV. Prevalence and risk factors for anaemia in pregnant women: a population-based prospective cohort study in China. Paediatr Perinat Epidemiol 2009; 23(4):282-91.

25. Nazli R, Khan MA, Akhtar T, Mohammad NS, Aslam H, Haider J. Frequency of thrombocytopenia in pregnancy related hypertensive disorders in patients presenting at tertiary care hospitals of Peshawar. Khyber M ed Univ] 2012; 4 (3):101-105.

26. Rahim R, Nahar K, Khan IA. Platelet count in 100 cases of pregnancy induced hypertension. M ymensingh M ed J. 2010; 19 (1):5-9.

27. Hossain N, Shah N, Khan N, Lata S, Khan NH. Maternal and Perinatal Outcome of Hypertensive Disorders of Pregnancy at a Tertiary Care Hospital. J Dow Univ Health Sci 2011; 5(1): 12-16. 